http://jmscr.igmpublication.org/home/

ISSN (e)-2347-176x ISSN (p) 2455-0450

crossref DOI: https://dx.doi.org/10.18535/jmscr/v7i10.127

\title{
Pneumocephalus after Epidural Injection of Steroid: A Rare Case Report
}

\author{
Authors \\ Dr K. Sai Lavanya ${ }^{1}$, Dr Shiny Priyadarshini ${ }^{2}$, Dr Krishna Chaitanya ${ }^{3 *}$, \\ Dr Mushahida ${ }^{4}$, Dr Shashank Mudhelli ${ }^{5}$ \\ Narayana Medical College, Nellore \\ *Corresponding Author \\ Dr Krishna Chaitanya
}

\begin{abstract}
Lumbar epidural steroid injections are commonly performed for the treatment of low back and lower extremity radicular pain. A patient aged 53 years with L4-L5 spondylosis with radiculopathy was given lumbar epidural steroid injection using loss of resistance to air technique with $3 \mathrm{ml}$ of air. 2hrs later, she developed severe headache with an episode of non-projectile vomiting, followed by irritability, breathlessness, unconsciousness. Patient was resuscitated immediately and shifted to ICU for further management. An MRI was done which revealed pneumocephalus and patient was treated symptomatically and discharged after complete recovery after 3 days from the hospital. We conclude that the amount of air used to confirm LORA should be minimised and the use of saline avoids such complications.

Keywords-epidural anaesthesia, spondylosis, pneumocephalus.
\end{abstract}

\section{Introduction}

Epidural steroid injection is a widely used procedure for relief of symptoms associated with prolapsed intervertebral disc, spinal canal stenosis, herniated disc, degenerative disc with radiculopathy. It is of benefit with rare rate of major side-effects.

Common methods for identification of the epidural space is "Loss Of Resistance To Air" (LORA) and "Loss Of Resistance To Saline" (LORS). ${ }^{(1)}$

Although widely used, it comes with a rare complication of inadvertent injection of air in subdural/subarachnoid space, which can lead to symptoms of increased intracranial pressure. Here we report a case of pneumocephalus following lumbar epidural steroid injection where the epidural space was identified using "loss of resistance to Air:".

\section{Case Report}

A 53 year old female patient was referred from orthopedic OPD with a chief complaint of low back pain since 2 months, radiating to right lower limb, MRI showed prolapsed intervertebral disc at L4-L5 and hence planned for an epidural steroid injection for pain relief.

There was no history of trauma or fall. She is a known diabetic and hypertensive on regular medication with T. Metformin 500mg, T. Amlodipine 5mg and T. Telmisartan 40mg.

In the operation theater, venous access was secured, all the basic monitors were connected and baseline recordings noted.

The patient's back was prepared for epidural steroid injection under sterile aseptic precautions. Epidural space was identified at L4-L5 in the second attempt 


\section{JMSCR Vol||07||Issue ||10||Page 751-754||October}

using "LORA" (3-4 ml air) technique and 40mg methylprednisolone $+2 \%$ lignocaine with normal saline diluted to $10 \mathrm{cc}$ was administered.

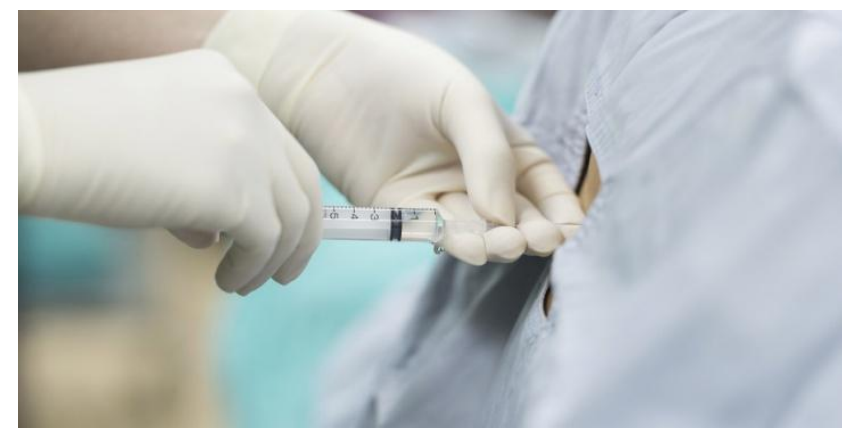

Following the procedure, the patient was shifted to recovery unit after confirming that all the vitals were stable and assessed for sensory and motor power.

Two hours later, the patient developed severe headache, associated with 1 episode of vomiting. Patient's condition worsened and became irritable, breathless and unconscious. On examination, RR: 36/min, HR: 136beats/min, BP: 88/60mmHg, SpO2 : $86 \%$ which was falling, CVS: S1S2 +, RS: BAE+ with coarse crepitations on the right side, pupils were bilaterally reacting to light equally. There was no movement of both upper and lower limbs. Patient was immediately intubated and shifted to ICU and her vitals were stabilised.

Neurology opinion was obtained and MRI brain was done which revealed pneumocephalus $15 \mathrm{~mm}$ in frontal and temporal horn of $\mathrm{B} / \mathrm{L}$ ventricles. She was managed symptomatically in ICU, extubated $24 \mathrm{hrs}$ later and shifted to ward and discharged after a 2 days.
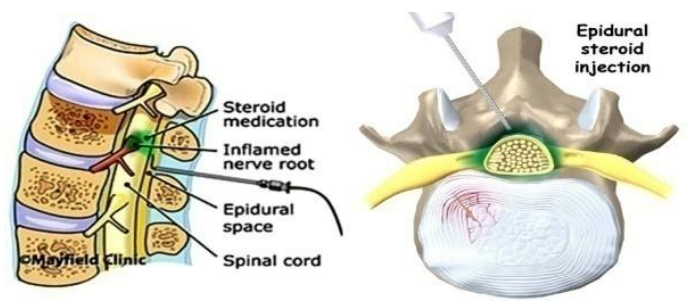
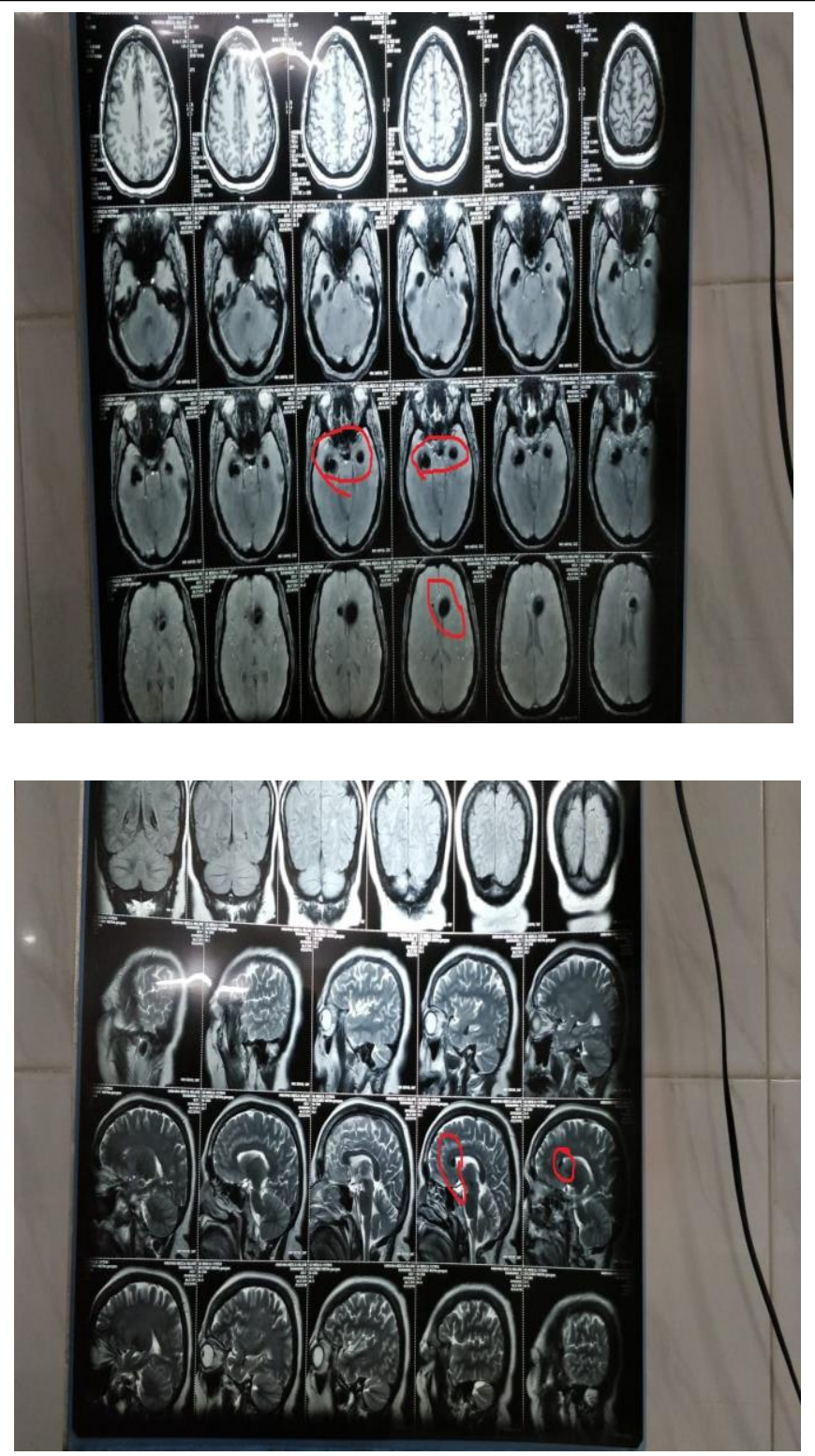

\section{Discussion}

Epidural space can be identified using loss of resistance technique (using air or saline), detection of negative pressure (hanging drop and inflated balloon), besides other methods such as ultrasonography guided and fluoroscopy guided. LORA and loss of resistance to saline (LORS) are commonly used ${ }^{[7],[8]}$ and carry with them their own advantages and disadvantages. The success of epidural injection depends on correct identification of epidural space. Using LORS, space can be well appreciated but may dilute local anesthetic solution and it is difficult to ascertain subarachnoid puncture. On the other hand, LORA may lead to false-positive results because of air being compressible. [9],[10] Other complications related to LORA 
technique were compression of nerve roots and spinal cord, subcutaneous emphysema, incomplete analgesia, paresthesia, Pneumocephalus, hypotension, bradycardia, apnea.

Pneumocephalus (PC) basically means air/gas in the cranial cavity. Although common in neurosurgery and neuroradiology, ${ }^{[4],[5]}$ it is rarely seen after epidural injection as a consequence of unintentional dura puncture, resulting from the introduction of air into subarachnoid/subdural space and subsequent cranial migration. [2],[3]

Incidence of Pneumocephalus is unknown and only few cases are reported per year. ${ }^{[6]}$ Complication related to procedure per se are hypotension, postdural puncture headache (PDPH), dizziness, transient paraplegia, and Pneumocephalus.

Air can inadvertently enter the cranium through subdural/subarachnoid space during epidural space identification since in our case there was no cerebrospinal fluid leakage; hence, ruling out the possibility of subarachnoid puncture, the possible explanation for Pneumocephalus could be that air might have entered the cranium through subdural space. Subdural space refers to space between dura and arachnoid mater, filled with small volume of serous fluid, and connected to cranium via second sacral vertebrae and the possible route for air to migrate intracranially.

Signs and symptoms following migration of air comprise of headache, nausea and vomiting, disorientation, agitation, decreased level of consciousness, seizures, and dysarthria, depend on amount and spread of air.

Air volume as low as $2 \mathrm{ml}$ can cause Pneumocephalus.

Pneumocephalus can be diagnosed early on the basis of clinical features: headache was abrupt in onset (within 1-2h), and not relieved on lying down.

Diagnosis is best confirmed radiologically.

Treatment: Symptomatic. Oxygen supplementation in the supine position to accelerate absorption of intracranial air and rapid denitrogenation, prophylactic antibiotics, analgesics, and adequate hydration.
Pneumocephalus can be prevented using saline instead of air, or if air is to be used maximum $2 \mathrm{ml}$ should be used. We should identify that the headache occurs commonly immediately after the puncture. Likewise, we should recognize that symptoms are similar to those of PDPH and should be established by imaging techniques. We should be able to assess that pneumocephalus may be spontaneously absorbed and treated symptomatically.

\section{Conclusion}

When loss of resistance to air is used, it is better to use minimal amount. Epidural steroid injection with loss of resistance with normal saline is better when compared to air and when dura is punctured, to avoid these type of complications.

\section{References}

1. Guarino AH, Wright NM. Pneumocephalus after a lumbar epidural steroid injection. Pain Physician 2005;8:239-41.

2. 2Wang JC, Tsai SH, Liao WI. Pneumocephalus after epidural anesthesia in an adult who has undergone lumbar laminectomy. J Neurosurg Anesthesiol 2014;26:261-3.

3. Nafiu OO, Urquhart JC. Pneumocephalus with headache complicating labour epidural analgesia: Should we still be using air? Int J Obstet Anesth 2006;15:237-9.

4. Reasoner DK, Todd MM, Scamman FL, Warner DS. The incidence of pneumocephalus after supratentorial craniotomy. Observations on the disappearance of intracranial air. Anesthesiology 1994;80:1008-12.

5. Peterson HO, Kieffer SA. Neuroradiology. Vol. 1. New York: Hayon and Row; 1984. p. 127-30.

6. Hawley JS, Ney JP, Swanberg MM. Subarachnoid pneumocephalus from epidural steroid injection. Headache 2005;45:247-8. 
7. de Andrés JA, Gomar C, Calatrava P, Nalda MA. Comparative study of detection methods in epidural anesthesia: Episensor and loss of resistance. Rev Esp Anestesiol Reanim 1990;37:330-4.

8. Mateo E, López-Alarcón MD, Moliner S, Calabuig E, Vivó M, De Andrés J, et al. Epidural and subarachnoidal pneumocephalus after epidural technique. Eur J Anaesthesiol 1999;16:413-7.

9. Davidson JT. Identification of the epidural space. Anesthesiology 1966;27:859.

10. Zaccara G, Muscas GC, Messori A. Clinical features, pathogenesis and management of drug-induced seizures. Drug Saf 1990;5:109-51.

11. Ajar AH, Rathmell JP, Mukherji SK. The subdural compartment. Reg Anesth Pain Med 2002;27:72-6.

12. Hawley JS, Ney JP, Swanberg MM. Subarachnoid pneumocephalus from epidural steroid injection. Headache 2005;45:247-8. 